\title{
Acute Myocardial Infarction in Elderly Patients. Comparative Analysis of the Predictors of Mortality. The Elderly Versus the Young
}

\author{
Marisa F. Leal, Newton Fernando Stadler de Souza Filho, Hermínio Haggi Filho, \\ Estela Regina Klosoviski, Eva Cantalejo Munhoz \\ Curitiba, PR - Porto Alegre, RS - Brazil
}

\begin{abstract}
Objective - To study the in-hospital evolution of patients aged 65 years and older, with acute myocardial infarction, who were treated by direct coronary angioplasty with no fibrinolytic therapy.
\end{abstract}

Methods - We studied 885 patients divided into 2 groups as follows: group I (GI) - 293 (33.4\%) patients aged $\geq 65$ years ( $72 \pm 5$ years), and group II (GII) - 592 patients aged $<65$ years $(57 \pm 9$ years). Multivessel disease was more frequent in $G I(63.5 \% \times 49.7 \%$; $p=0.001)$. A greater number of GII patients were class I or II of the clinical Killip-Kimball classification (K) $(80.2 \% x$ $67.2 \%$; $p=0.00002)$, while a significant number of GI patients were KIII and KIV (24.3\% x 12.8\%; $p=0.00003)$.

Results - Group I had a lower index of success $(84.6 \%$ $x$ 94\%; $p=0.0002)$ and a greater in-hospital mortality $(12.2 \% \times 4.7 \% ; p=0.00007)$. The predictors of mortality in GI were as follows: previous infarction $(20.5 \% \times 6.3 \%$; $p=0.02)$, anterior location $(13.4 \% \times 6.4 \% ; p=0.03)$, and male sex $(10.4 \% \times 4.4 \%$; $p=0.007)$.

Conclusion - Elderly patients had more severe acute myocardial infarction and more extensive disease, a lower index of success, and greater in-hospital mortality. Previous infarction, anterior location and male sex were identified as predictors of mortality in the elderly group (GI).

Keywords: acute myocardial infarction, coronary angioplasty, the elderly

Centro de Diagnose Cardiovascular/Aliança Saúde PUCPR - Santa Casa - Curitiba, Universidade Federal do Rio Grande do Sul - Porto Alegre

Mailing address: Marisa F. Leal - Centro de Diagnose Cardiovascular - Praça Rui Barbosa, 694 - 80010-030 - Curitiba, PR, Brazil - E-mail: cdcv@cdcv.com.br English version by Stela Maris C. e Gandour
In the coming decades, as has been occurring in developed countries, Brazil will experience the process of population aging. The intensity of this process is expected to place Brazil's population as the $6^{\text {th }}$ most elderly in absolute numbers within the first 25 years of this millennium. Life expectancy in Brazil increased from 43 years in 1950 to 65 years in $1991^{1}$. It has been projected to reach 72 years in 2020. Because of the large extension and diversity of the country leading to regional differences, this process will not occur in an even manner, being more marked in the southern and southeastern regions than in the northern and northeastern regions ${ }^{2}$. In the southern region, where the sample of this study was collected, and according to the statistics of 1993, life expectancy is 68.6 years, which is 3 years greater than the life expectancy of the general Brazilian population ${ }^{1}$.

As people age, a trend towards a change in the pattern of morbidity and mortality occurs. At the beginning of the 20th century, the major cause of death in Brazil was infectious disease, which has been replaced currently by cardiovascular causes. Of all chronic diseases, cardiovascular diseases account for the greatest number of hospitalizations in Brazil ${ }^{3}$, and they appear as the cause of death in almost half of the records in the Brazilian capitals in the southern and southeastern regions ${ }^{2}$.

Compared with the general population, the elderly have a greater number of diseases, mainly chronic, and a high prevalence of coronary artery diseases ${ }^{3}$. Approximately $70 \%$ of the individuals above 70 years of age have coronary artery disease, which is the major cause of morbidity and mortality in that age group. Acute myocardial infarction and sudden death are frequent initial manifestations of coronary artery disease in the elderly; therefore, early diagnosis is paramount to prevent these complications, and the peculiarities inherent to each age group must be known ${ }^{4}$. These factors cause the prevalence of the disease diagnosed during life to be less than half of the cases of significantly obstructive atherosclerotic disease found at autopsies ${ }^{5}$. 
Initially reported by Hartzler ${ }^{6}$, coronary angioplasty for treating acute myocardial infarction was performed in patients who were or were not using thrombolytic agents prior to the procedure. Direct coronary angioplasty without the previous use of thrombolytic agents has been routinely performed at our service since 1982, and technical and pharmacological resources resulting from different studies have been incorporated throughout these years. Among those resources, we highlight the use of coronary stents that optimize the results, especially the incidence of recurring ischemia and late restenosis ${ }^{7}$, and the use of antithrombotic agents.

The objective of this study was to compare the inhospital evolution of patients aged $\geq 65$ years with that of patients $<65$ years, who were hospitalized within the first 24 hours after acute myocardial infarction and were treated with mechanical reperfusion followed by direct coronary angioplasty with no previous antithrombotic therapy.

\section{Methods}

We carried out a retrospective study of consecutive procedures of mechanical recanalization followed by direct coronary angioplasty for myocardial reperfusion as a treatment for acute myocardial infarction within the first 24 hours of its presentation, with no pharmacological reperfusion, then defined as primary angioplasty.

The study comprised a total of 861 patients undergoing 885 direct coronary angioplasty procedures divided into 2 groups as follows: group I (GI), comprising 288 patients aged $\geq 65$ years ( $72 \pm 5$ years) and undergoing 293 (33.1\%) procedures; and group II (GII), comprising 573 patients aged $<65$ years ( $57 \pm 9$ years) and undergoing 592 $(66.9 \%)$ procedures.

The diagnosis of acute myocardial infarction was confirmed by clinical, electrocardiographic, and hemodynamic findings. The patients studied were admitted consecutively. The following characteristics were not considered criteria for exclusion: cardiac arrest as a presentation of acute myocardial infarction (sudden death), cardiogenic shock, bradyarrhythmias or tachyarrhythmias, multivessel lesions, impairment of the left coronary trunk, previous myocardial infarction, and previous myocardial revascularization.

All patients were classified according to the KillipKimbal classification ${ }^{8,9}$, but a group of patients could not undergo that classification because they were experiencing cardiac arrest or shock associated with complete atrioventricular block or ventricular tachycardia. This group was called nonclassified. All patients received nitrates, sedatives, analgesics, 10,000 units of intravenous heparin and acetylsalicylic acid. Once the patient or his guardian provided the formal written consent, diagnostic cardiac catheterization and interventional therapy were performed. Direct coronary angioplasty was performed after mechanical recanalization with a 0.014 " guidewire when the vessel responsible for the acute myocardial infarction was totally occluded (TIMI 0 ) or directly upon the lesion (TIMI I, II, and III) ${ }^{10}$. Balloon and coronary stents were used for direct coronary angioplasty. Antiarrhythmic, vasopressor, and vasodilator drugs, beta- blockers and abciximab, invasive continuous hemodynamic monitoring, transitory pacemaker, and the use of intraaortic balloon followed specific and individualized indications. After the procedure, all patients were referred to the coronary care unit for electrocardiographic, blood pressure, and hemodynamic monitoring.

Success on reperfusion (direct coronary angioplasty) was defined as the presence of TIMI II and III degree of flow after coronary angioplasty, and luminal diameter $>50 \%$ in the absence of major complications, such as death, emergency surgery, and occlusion after the procedure.

Data were stored and analyzed with Epi Info software, version 6.0, which through the TABLES command produces contingency tables to test the associations between 2 factors. The software calculates the relative risk and its statistical significance (through the $95 \%$ confidence interval) using the following formula: $\mathrm{RR}=(\mathrm{a} / \mathrm{H} 1)(\mathrm{c} / \mathrm{H} 2)$, based on values of the contingency table. Chi-square values were calculated with the Yates correction, in which " $p$ " values were given for a degree of freedom. When 1 of the values of the contingency table was $<$ 5, we used the corrected Fisher exact test (2-tailed).

SPSS software, version 8.0, was used for the actuarial curve of survival and the Kaplan-Meier method for accumulated risks.

The Student $t$ test, chi-square test, Fisher exact test, median test, and Kruskal-Wallis test were applied for independent samples, and the binomial distribution for the case of a single sample. The statistical significance level adopted was $5.0 \%(\mathrm{p}<0.05)$.

\section{Results}

Of the total sample of 885 procedures, 288 patients (293 procedures) were 65 years of age or older (GI), and 573 patients (592 procedures) were less than 65 years (GII).

Of the GI patients, 177 (61.4\%) were males and 111 $(38.4 \%)$ were females, with a mean age of $72 \pm 5.3$ years, and, of the GII patients, 435 (79.1\%) were males and 120 were females $(20.9 \%)$ with a mean age of $57 \pm 9$ years. A progressive increase in the frequency of the female sex in more advanced age brackets was observed, and from 65 years of age on this difference was less significant, with a predominance of females after the age of 80 years (fig. 1).

Previous infarction was present in 39 (13.3\%) GI patients and in $95(16 \%)$ GII patients $(\mathrm{p}=0.3)$. Nineteen GI patients $(6.5 \%)$ and $28(4.7 \%)$ GII patients had a previous myocardial revascularization surgery $(\mathrm{p}=0.3)$.

Examining the risk factors for coronary artery disease (systemic arterial hypertension; diabetes mellitus; familial history of coronary artery disease; dyslipidemias; obesity; and smoking), smoking was not only the most frequently found but also had a high significance in GII (patients $<65$ years) $(42 \% \times 22.8 \%$; $=0.0000001)$.

A greater number of GII patients were in classes I or II of the Killip-Kimball clinical classification (K) $(80.2 \% \mathrm{x}$ $67.2 \%$; $\mathrm{p}=0.00002$ ), while KIII and IV significantly predominated in GI ( $24.3 \%$ x $12.8 \%$; $\mathrm{p}=0.00003)$. Twenty-five patients were considered nonclassified (NC) (tab. I). 


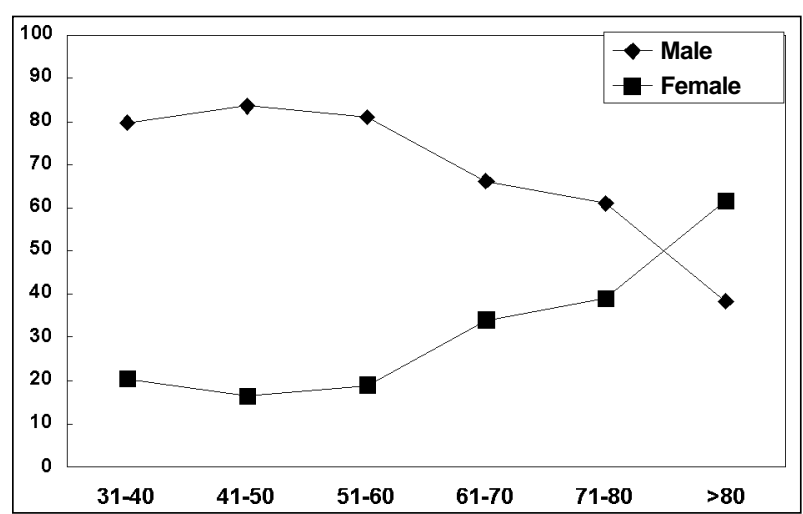

Fig. 1 - Percentage values of the incidence of sex and age group in a 10-year period.

The location of acute myocardial infarction was similar, with no significant differences between the 2 groups: anteriorwall $(45.1 \% \times 41.6 \%)$, inferior wall $(41.6 \% \times 41 \%)$, and lateral wall (15.1\% x $13.9 \%)$, for GI and GII, respectively.

The mean duration of reperfusion was $327 \pm 234$ minutes for GI patients (the elderly) and $305 \pm 225$ minutes for GII patients ( $<65$ years).

No difference regarding the degree of flow was observed between the groups (tab. II).

Multivessel disease, defined as atherosclerotic disease obstructing more than $70 \%$ of the lumen of more than 1 major coronary artery or their branches, or both, found on coronary angiography was more frequent and significant in GI: 186 patients $(63.5 \%$ x $49.7 \%$; $\mathrm{p}=0.001)$.

Success was obtained in $797(90.05 \%)$ procedures and was significantly greater in GII, $549(94.0 \%)$, than in GI, 248 $(84.6 \%)(\mathrm{p}=0.0002)$.

The $7.2 \%$ in-hospital mortality when analyzed for both groups was significantly greater in GI, 36 (12.2\%) patients, as compared with $28(4.7 \%)$ patients in GII $(\mathrm{p}=0.00007)$. This represented a relative risk of death in patients $\geq 65$ years (GI) of 2.6 per procedure.

The mean age of the GI patients (age $\geq 65$ years) who died was $75 \pm 6$ years, significantly greater than the mean age of those who survived $(71 \pm 5$ years $)(p=0.002)$.

\begin{tabular}{|lrrrr|}
\hline \multicolumn{5}{|c|}{ Table I - Killip-Kimbal classification of the patients with acute } \\
myocardial infarction \\
8,9
\end{tabular}

\begin{tabular}{|c|c|c|c|}
\hline \multicolumn{4}{|c|}{ Table II - Coronary flow degree according to TIMI ${ }^{10}$} \\
\hline TIMI & GI & GII & $P$ \\
\hline 0 & $226(77.1 \%)$ & $(76 \%)$ & NS \\
\hline I & $37(12.6 \%)$ & $78(13.2 \%)$ & NS \\
\hline II & $19 \quad(6.5 \%)$ & $48 \quad(8.1 \%)$ & NS \\
\hline III & $11 \quad(3.7 \%)$ & $16 \quad(2.7 \%)$ & NS \\
\hline
\end{tabular}

Smoking, the only risk factor for coronary artery disease significantly more frequent among GII patients $(\mathrm{p}=0.0000001)$, showed no significance when correlated with mortality $(18 \%$ GIx $28 \%$ GII; $\mathrm{p}=0.08)$.

In-hospital reocclusion was $8.8 \%$ for the patients $>65$ years and $4.4 \%$ for those $<65$ years, but no significance between the 2 groups was observed ( $\mathrm{p}=0.11$ ).

The following findings were identified as predictors of in-hospital mortality: presence of previous infarction, infarction of the anterior wall, and the male sex (tab. III).

The KIII and KIV functional classes were risk factors for both groups. When analyzing the summation of the $\mathrm{KIII}$, KIV, and NC functional classes, mortality was $30.2 \%$ in GI and $20.5 \%$ in GII, but no statistically significant difference was observed $(p=0.14)$. The comparison between the groups is shown in figure 2 .

Mortality was greater in females (15.4\%) as compared with that in males (10.4\%) in GI, the same occurring in GII, which had a $6.7 \%$ mortality in females as compared with a $4.4 \%$ mortality in males, but with no significant difference. When this same analysis was applied to compare the 2 groups (GI x GII), mortality was greater and more significant in GI males $(10.4 \% \times 4.4 \%$; $\mathrm{p}=0.007)$ but with a borderline significance, among females, showing only a trend $(15.4 \% \mathrm{x}$ $6.7 \% ; p=0.053$ ) (fig. 2 , graph 1).

Patients with single-vessel and multivessel disease in GI ( $\geq 65$ years) had a similar mortality $(12.1 \%$ and $12.4 \%$, single-vessel and multivessel disease, respectively), while in GII patients ( $<65$ years), mortality was significantly greater for those with multivessel lesions (7.5\%) as compared with that of patients with single-vessel disease $(1.7 \% ; \mathrm{p}=0.0009)$.

Patients with single-vessel disease in GI had significantly greater mortality than those with single-vessel disease in GII (11.1\% x 1.7\%; $\mathrm{p}=0.0004$ )(fig. 2, graph 2). Patients with multivessel disease in GI had mortality of $12.4 \%$ as compared with $7.5 \%$ for those in GII, but with no significance $(\mathrm{p}=0.1)$.

Analyzing in-hospital reocclusion in regard to mortality in GI and GII groups, we observed that 5 of the 26 procedures occurred in GI (19.2\%) and 3 of 26 procedures occurred in GII $(11.5 \%)$; $(\mathrm{p}=0.35)$.

In the late follow-up, after hospital discharge, the mortality rate was $18.8 \%$. The Kaplan-Meier actuarial curve showed $93.5 \%$ survival in the $1^{\text {st }}$ year, $91.42 \%$ in the $2^{\text {nd }}$ year, and $75 \%$ survival in 5 years for the elderly.

\section{Discussion}

Some authors have reported that acute myocardial infarction in the elderly deserves special consideration be-

\begin{tabular}{|lccc|}
\hline \multicolumn{4}{|c|}{ Table III - Predictors of in-hospital mortality } \\
\hline Predictors of mortality & $\begin{array}{c}\geq 65 \text { years } \\
\text { (GI) } \%\end{array}$ & $\begin{array}{c}<65 \text { years } \\
\text { (GII) } \%\end{array}$ & $\mathrm{P}$ \\
\hline Previous infarction & 20.5 & 6.3 & 0.02 \\
Anterior AMI & 13.4 & 6.4 & 0.03 \\
Male sex & 10.4 & 4.4 & 0.007 \\
\hline
\end{tabular}




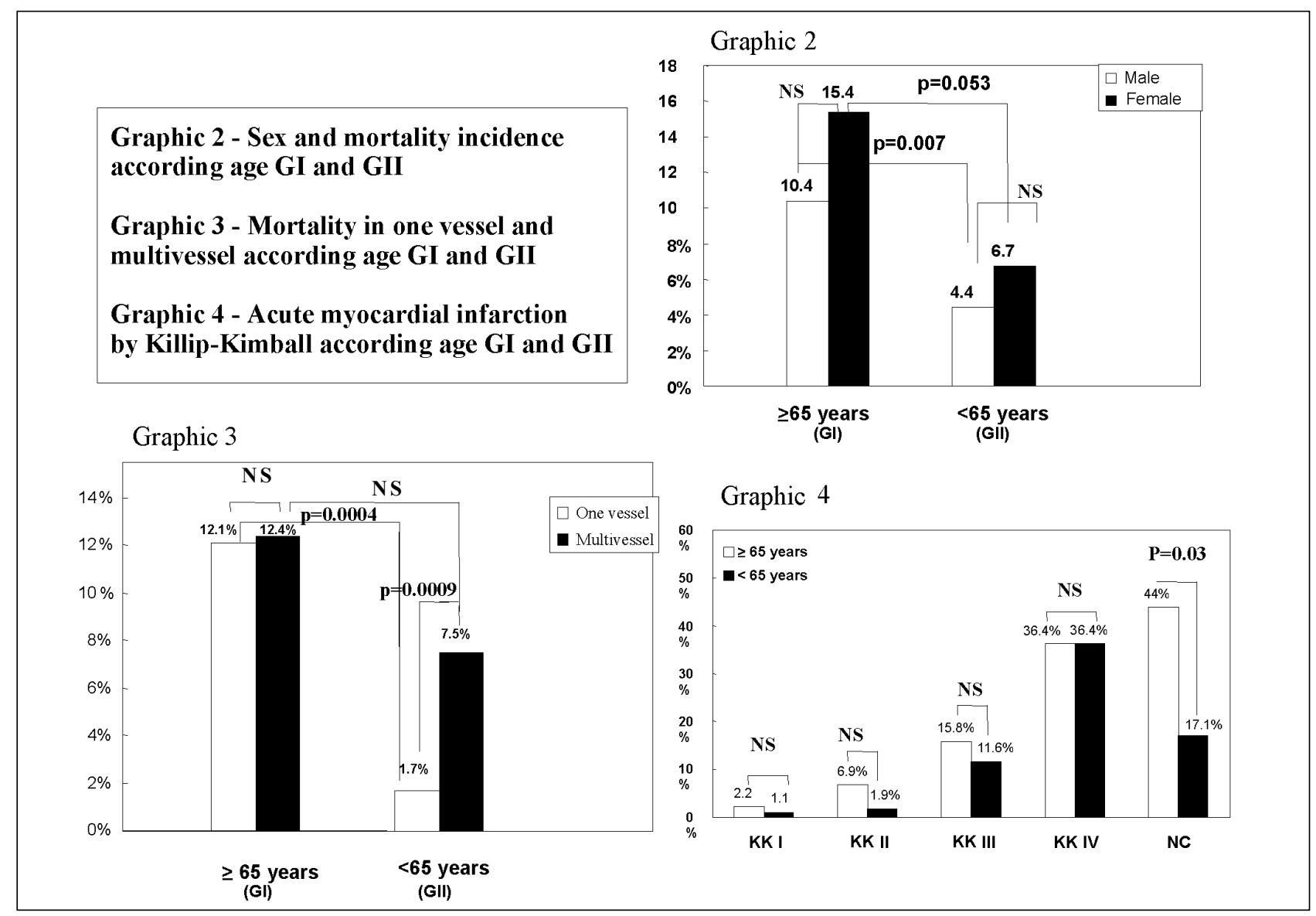

Fig. 2 - Analysis of mortality according to sex, vessels impaired, and Killip-Kimball functional class in patients aged $\geq 65$ years (GI) and $<65$ years (GII).

cause of high in-hospital morbidity and mortality and the pessimistic prognosis during in-hospital stay ${ }^{11-13}$. Clinical studies have shown in-hospital mortality ranging from $32 \%$ to $60 \%$ in this age group, and it could reach $93 \%$ to $100 \%$ in the presence of cardiogenic shock ${ }^{14}$. These findings suggest that the reperfusion methods should be used in that population with confirmed advantages ${ }^{15}$.

Direct coronary angioplasty performed in elderly patients ( $>75$ years) was reported as a high-risk procedure due to the greater index of complications. The in-hospital mortality reported is greater in patients in this age group $(0.8$ to $8.5 \%)$ as compared with that in younger patients ( 0 to $1.8 \%)^{11-14,16-19}$. Hartzler et al ${ }^{20}$ reported a 2.6 relative risk for mortality after direct coronary angioplasty in patients $>70$ years, and, in this study, we found the same 2.6 relative risk using a cutoff for age of 65 years. It is worth noting that the mean age in GII (patients $<65$ years) was $57 \pm 9$ years, and, in the elderly group (GI), the mean age was $72 \pm 5.3$ years, indicating that most patients in GII could be very close to the cutoff for age (fig. 3). But because females have acute myocardial infarction 10 years later than males do, this can eventually represent a bias in the cutoff for age between males and females.

This study showed that elderly patients with acute myocardial infarction are admitted to the hospital with more severe clinical findings than those of younger patients. In the elderly, atherosclerotic arterial disease is more extensive with multivessel involvement. Primary direct coronary angioplasty in acute myocardial infarction in the elderly had lower indices of success for reperfusion than those found in the younger patients; nevertheless, the procedure had very positive indices $(84.6 \%)$ and a low in-hospital mortality $(12.2 \%)$, which are in accordance with findings of other studies for that age group ${ }^{21-23}$.

In-hospital mortality correlated with the clinical presentation, ie, with the Killip-Kimbal functional class, being significantly greater in functional classes III and IV in both groups (fig. 2, graph 3). But when the 2 groups were compared with each other, the differences were not statistically significant, suggesting that the severity of the clinical presentation in acute myocardial infarction could be more important than age at presentation of the acute myocardial infarction.

Direct coronary angioplasty may be used as a method for myocardial reperfusion in patients with cardiogenic shock and lead to a significant reduction in mortality as reported by O'Keefe et $\mathrm{al}^{24}$. Their results were the first accepted and clearly defined indication published in the international literature of the use of percutaneous (mechanical) reperfusion in acute myocardial infarction. Considering the patients with cardiogenic shock, the authors observed a $36 \%$ mortality, which was lower than that reported in previous clinical studies, and coincided with the results by 
Mattos et al ${ }^{25}$. These results were also comparable to those reported by Lee et al ${ }^{26}$ in a pioneering study, which spawned the acceptance of primary direct coronary angioplasty in patients with Killip-Kimball functional classes III and IV. These results represented more than isolated numbers, a never published improvement in mortality indices, or even better, in the perspective of survival for patients with acute myocardial infarction and cardiogenic shock (a 50\% mortality for patients admitted with cardiogenic shock). This has opened a new and promising path for research in cardiology. Maintaining patency in the artery is fundamental for the survival of these patients.

The anterior wall as the site of the infarction, the presence of previous infarction, and the male sex were identified as predictors of mortality in the group of patients $\geq 65$ years. Even though the female sex was more prevalent in the elderly group and had the greatest percentage of in-hospital deaths, these findings did not reach significance, representing only a trend in the statistical analysis $(\mathrm{p}=0.053)$. Because females have acute myocardial infarction 10 years later than males do, this may eventually mean a bias in the cutoff for age ${ }^{27}$.

Even though smoking was more frequent and significant in GII $(22 \% \times 42 \%$; $=0.0000001)$, it showed no correlation with mortality $(\mathrm{p}=0.08)$.

In a recent study, Munhoz and Oliveira ${ }^{28}$ reported an unfavorable impact on in-hospital mortality related to inhospital reocclusion in acute myocardial infarction in patients treated with primary direct coronary angioplasty. In the present study, in-hospital reocclusion was not shown to be a predictor of mortality in the groups. As in-hospital reocclusion is not a frequent phenomenon, a greater number of patients would be required, which would demand an excessively long time for sample collection. Even though that number of patients was sufficient for the analysis of other phenomena, it would probably be lower than the number required to analyze the phenomenon of reocclusion (5 patients in GI and 3 in GII, mortality of $19.2 \%$ x $11.5 \%$; $\mathrm{p}=0.35$ ).

The presence of multivessel lesions with a greater extension of atherosclerotic coronary artery disease and statistical significance $(63.5 \% \times 49.7 \%$; $\mathrm{p}=0.001)$ in GI was not also identified as a predictor of mortality. This confirmed the previous findings ${ }^{28}$ that the extensiveness of the disease, which is a decisive factor in the therapeutical approach to atherosclerotic coronary artery disease and has great prognostic importance in the long run, does not represent an unfavorable impact on the initial approach, the in-hospital phase, of acute myocardial infarction. This also suggests that the approach of the artery responsible for acute myocardial infarction could represent a more significant impact for the patient in this phase, once again suggesting that revascularization of the artery responsible for acute myocardial infarction is more important than complete revascularization in the acute phase of acute myocardial infarction.

Our results for late evolution of global survival in acute myocardial infarction in the $1^{\text {st }}$ year $(93.5 \%), 2^{\text {nd }}$ year $(91.4 \%)$, and $5^{\text {th }}$ year $(75 \%)$ following hospital discharge are better than those reported in previous studies, with no therapy for myocardial reperfusion, mortality for which ranged from $28 \%$ to $40 \%$ in the $1^{\text {st }}$ year and was $47 \%$ in the $2^{\text {nd }}$ year ${ }^{29,30}$.

The mean age of the GI (age $\geq 65$ years) patients dying was $75 \pm 6$ years, which was significantly greater than the mean age of the surviving patients ( $71 \pm 5$ years $) ;(\mathrm{p}=0.002)$. These findings are in accordance with those in previous publications. Advanced age is a risk factor in the evolution of acute myocardial infarction. The TIMI Risk Score for STEMI ${ }^{31}$ reports that age $>65$ years is the major scoring factor among the predictors of mortality, contributing with an increase from $2.2 \%$ to $4.4 \%$; however, we did not use this score in our study.

In conclusion, patients aged $\geq 65$ years have more severe acute myocardial infarction and more extensive coronary artery disease. When compared with the younger group, these patients have a lower index of success and higher in-hospital mortality. The presence of previous infarction, the anterior wall as the site of acute myocardial infarction, and the male sex were identified as predictors of death in elderly patients. Our findings both in the in-hospital and late phases suggest that coronary angioplasty may be the therapy of choice and not an exception in elderly patients of both sexes. Further randomized and controlled studies are required to confirm these findings. Being an observational, retrospective, nonrandomized study with no control group may constitute the major limitation for extrapolating the results of our study to other populations.

\section{References}

1. IBGE. Instituto Brasileiro de Geografia e Estatística. Anu Estat Brasil. Rio de Janeiro 1993; 53: 2.29-2.41.

2. Ramos LR, Veras RP, Kalache A. Envelhecimento populacional: uma realidade brasileira. Rev Saúde Públ 1987; 21: 211-24.

3. Veras RP, Ramos LR, Kalache A. Crescimento da população idosa no Brasil: transformações e conseqüências na sociedade. Rev Saúde Públ 1987; 70: 225-33.

4. Wajngarten M, Pivotto LBP. Arteriopatia coronariana no idoso. Aspectos diagnósticos. In: Jacob Filho W (Coord) Arteriopatias no Idoso. São Paulo, FMUSP, 1992: 39-43.

5. Weisfeldt ML, Lakatta EG, Gerstenblith G. Aging and the heart. In: Braunwald E. Heart Disease. A Textbook of Cardiovascular Medicine. $4^{\text {th }}$ ed. 1992; 2: 1656-69.
6. Hartzler GO, Rutherford BD, McConahay DR. Percutaneous Transluminal Coronary Angioplasty. Aplication for acute myocardial infarction. Am J Cardiol 1985; 53: C117-C121.

7. Grines CL, Cox DA, Stone GW, et al. Stent PAMI: 12 months results and predictors of mortality. J Am Coll Cardiol 2000; 35(suppl A): 402.

8. Killip T, Kimbal T. Treatment of myocardial infarction in a coronary care unit. A two year of experience with 250 patients. Am J Cardiol 1967; 20: 457-64.

9. Killip T, Kimbal T. A survay of coronary care unit: concep and results. Progr Cardiovasc Dis 1968: 11: 45-52.

10. TIMI - The thrombolysis in myocardial infarction trial - Phase I Findings. N Engl J Med 1985; 312: 932-6. 
11. Latting CA, Silverman ME. Acute myocardial infarction in hospitalized patients over age 70. Am Heart J 1980; 100: 311-8.

12. OlmstedWL, GrodenDL, Silverman, ME. Prognosis in survivors of acutemyocardial infarction occurring at age 70 years or older. Am JCardiol 1987; 60: 971-5.

13. Tofler GH, Muller JE, Stone PH, et al. Factors leading to shorter survival after acute myocardial infarction in patients ages 65 to 75 years compared with younger patients Am J Cardiol 1988; 62: 860-7.

14. Telerman S, Franken RA, Kadri T, et al. Infarto agudo do miocárdio em pacientes acima de 70 anos. Estudo de 51 casos. Arq Bras Cardiol 1990; 55: 105-8.

15. Himbert D, Steg PG, Juliard JM, Neukirch F, Aumont C, Gourgon R. Eligibility for reperfusion therapy and ouctome in elderly patients with acute myocardial infarction. Eur Heart Journal 1994; 15: 483-8.

16. Lindsay Jr J, Reddy VM, Pinnow EE, et al. Morbidity and mortality rates in elderly patients undergoing percutaneous coronary transluminal angioplasty Am Heart J 1994; 128: 697-702.

17. Reynen K, Kunkel B, Gansser R, Martus P. PTCA in elderly patients: acute results and long-term follow-up. Eur Heart J 1993; 14: 1661-8.

18. Kelsey SF, Miller DP, Holubkov R, et al. Result of percutaneous transluminal coronary angioplasty in patientes 65 years of age (from the 1985 to 1986 National Heart, Lung, and Blood Institute's Coronary Angioplasty Registry). Am J Cardiol 1990; 66: 1033-8.

19. Maiello L, Colombo A, Gianrossi R, Thomas J, Finci L. Results of coronary angioplasty in patients aged 75 years and older. Chest 1992; 102: 375-9.

20. Hartzler GO, Rutherford BD, McConahay DR, Johnson WL, Giogi LV. "Highrisk" percutaneous transluminal coronary angioplasty. Am J Cardiol 1988; 61(suppl G): 33G-37G.

21. Grines GL, Browne KF, Marco J, RothhbaumD, Stone GW, O'keefe JA. A comparison of immediate angioplasty with thrombolytis therapy for acute myocardial infarction. N Engl J Med 1993; 328: 673-9.

22. Himbert D, Juliard JM, Steg PG, Badaoui G, Baleynaud S, Guludec DC. Primary coronary angioplasty for acute myocardial infarction with contraindication to thrombolysis. Am J Cardiol 1993; 71: 377-81.

23. Holland KJ, O'Neill WW, Bates ER, Pitt B, Topol EJ. Emergency percutaneous transluminal coronary angioplasty during acute myocardial infarction for patients more than 70 years of age. Am J Cardiol 1989; 63: 399-403.

24. O'Keefe JH, Rutherford BD, MacConahay DR, et al. Early and late results of coronary angioplasty without antecedent thrombolytic therapy for acute myocardial infarction. Am J Cardiol 1989; 64: 1221-30.

25. Mattos LAP, Cano MC, Maldonado G, et al. Emprego da angioplastia coronariana primária no infarto agudo do miocárdio em pacientes acima de 70 anos Arq Bras Cardiol 1992; 58: 181-7.

26. Lee TC, Laramee LA, Rutherford BD, et al. Emergency percutaneous transluminal coronary angioplasty for acute myocardial infarction in patients 70 years of age and older Am J Cardiol 1990; 66: 663-7.

27. Mosca L, Grundy SM, Judelson D, et al. ACC/AHA Guide to preventive cardiology for women. Circulation 1999; 99: 2480-4.

28. Munhoz EC, Oliveira PF. Significado clínico da reoclusão hospitalar no infarto agudo do miocárdio tratado com reperfusão mecânica e angioplastia coronariana primária. Arq Bras Cardiol 2000; 75: 429-35.

29. Uvarherlyi IS, Gatsonis C, Epstein AM, et al. Acute myocardial infarction in the medicare population - process of care and clinical outcomes. JAMA 1992;268: 2530-6.

30. Devlin W, Cragg D, Jacks M, et al. Comparison of outcome in patients with acute myocardial infarction aged $>75$ years with that in younger patients. Am JCardiol 1995; 75: 573-6.

31. Brawnwald E. Heart disease. A text book of cardiovascular medicine. Adapted from Morrow DA, Antman EM, Charlesworth A, et al. The TIMI Risk Scorle for STEMI - ST Elevation Myocardial Infarction: A Convenient, Bedside, Clinical Score for Risk Assessment at Presentation. $6^{\text {th }}$ Ed. 1999: chapter 35: 1151 